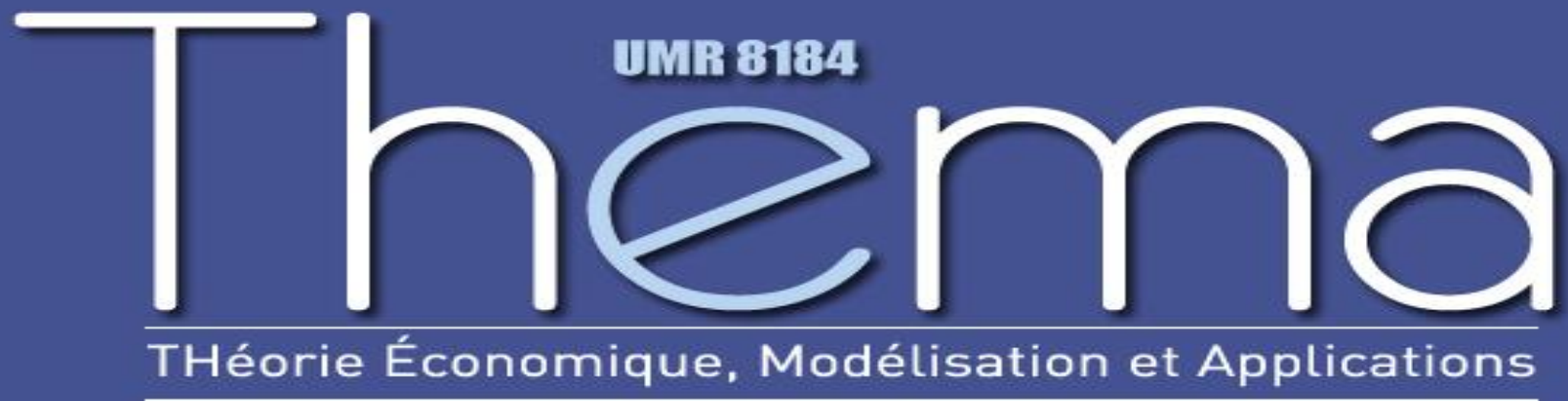

Thema Working Paper $n^{\circ}$ 2011-05

Université de Cergy Pontoise, France

\title{
Targeting and Child Poverty
}

Olivier Bargain

Olivier Donni

March, 2011 


\title{
Targeting and Child Poverty*
}

\author{
Olivier Bargain ${ }^{\dagger} \quad$ Olivier Donni ${ }^{\ddagger}$
}

March, 2011

\begin{abstract}
We examine the relative merits of targeting children within the household through price subsidies and cash transfers. To do so, we model the behavior of a household composed of one adult and one child. We then show that 'favorable' distortions from price subsidies may allow redistributing toward the child and then derive the conditions under which this redistributive scheme is more efficient than cash transfers. The framework is extended to account for possible paternalistic preferences of the social planner and for households composed of two adults with different preferences. Applied to a continuum of households, our approach is extended to the problem of child poverty alleviation. In contrast to the traditional view, we show that well-chosen subsidies may be more cost effective than cash transfers in reducing child poverty.
\end{abstract}

Key Words : indirect taxation, child benefit, targeting, intra-household distribution, social welfare, paternalism, labeling.

Classification JEL : D13, D31, D63, H21, H31.

${ }^{*}$ Acknowledgements: We are grateful to participants to various seminars and conferences (IIPF, PET, ESPE, IEA, RES) for invaluable advice and comments. All errors or omissions remain ours. Correspondence: Olivier Donni, 33 boulevard du Port, 95800 Cergy-Pontoise cedex, France. Email: olivier.donni@u-cergy.fr

${ }^{\dagger}$ University College of Dublin, CHILD and IZA

${ }^{\ddagger}$ Université de Cergy-Pontoise, THEMA, and IZA 


\section{Introduction}

The rise in child poverty is a recent source of concern for governments in developed countries (see Dickens and Ellwood, 2003). One of the most natural policies to improve child welfare consists in making cash transfers to families with children. Universal or means-tested child benefits are indeed in force in many industrialized countries. Yet this instrument raises issues of agency because cash transfers are not made directly to the intended recipients (i.e., children) but supplement the income of adults with the assumption that the standard of living of children will improve as well. Even if adults and children are altruistically linked, decisions regarding children's consumption are ultimately made by adults and the impact of cash transfers may be partially or totally neutralized by the intra-household redistribution process. An alternative strategy to improve child welfare consists in modifying the price structure by taxing or subsidizing some well-chosen goods. Contrary to cash transfers, which only have an income effect on household behavior, the change in consumer prices will create a distortion of the household consumption bundle. This can be favorable to children. In the case of subsidies on child-specific goods, for instance, price cuts may induce parents to purchase these goods and hence improve children's situation. ${ }^{1}$ Yet the final impact on child welfare remains unclear since the subsidies may be offset by a reduction of intra-household allocations to children. To which extent these 'favorable' distortions can be used as a targeting device and be more effective than cash transfers is an open question. More generally, and despite the large empirical literature on child poverty, there are surprisingly little theoretical grounds to assess the efficiency of indirect taxation in the light of intra-household mechanisms. ${ }^{2}$

The present paper contributes filling the gap. We suggest a simple model, in which households comprise a benevolent adult and a child, and characterize how variations in income and prices may affect the well-being of children and adults. By this means, we can examine the conditions under which price subsidies (or negative taxes) improve child

\footnotetext{
${ }^{1}$ There are several examples of tax reductions on child-specific goods, e.g., children's clothing in the United Kingdom and Ireland, milk and nappies in Canada, dairy products, child furniture, school equipment and a variety of other child goods in Russia. More generally, any tax or subsidy on goods consumed by parents and/or children may have, intentionally or not, an effect on child welfare.

${ }^{2}$ Cigno et al. (2003) present one of the rare studies that examine policies aiming to improve child welfare. Cremer and Pestieau (2001) study the optimal non-linear taxation of bequest using a model with altruistic parents.
} 
welfare and compare the cost efficiency of subsidies and cash transfers. We then study how results are altered when the social planner has paternalistic preferences and when the household includes two parents with different preferences. We finally extend our main results to a continuum of households, where income is the source of heterogeneity, to show how child poverty can be affected by subsidies. While the traditional view tends to favor cash transfers, which can be more easily targeted at the poorest, intra-household redistribution due to price distortions provides an argument in favor of subsidies.

As we focus exclusively on child welfare and child poverty, our work can be seen as an extension of Besley and Kanbur (1988) in the literature on targeting. ${ }^{3}$ While these authors study the relative effects of price tax/subsidies and cash transfers on poverty alleviation, we focus on the intra-household redistribution operated by these policies. Two additional remarks are important to position this paper in the literature. First, we focus on instantaneous financial poverty and not on questions and policies related to children's development, equality of opportunities and lifetime poverty. Second, our contribution is complementary to (but does not cover the case of) in-kind benefits and infra-marginal subsidies. $^{4}$ While a broad literature on cash versus in-kind transfers exists, the intrahousehold implications in this field too have received little attention and should be the object of future research (see the comments in the survey of Currie and Gahvari, 2008).

The paper is structured as follows. In Section 2, we describe the model of household behavior and its implications on the intra-household distribution of resources. In Section 3, we compute the impact of subsidies and cash transfers on child's welfare. In Section 4, we evaluate the efficiency of both policies in reducing child poverty, defined according to an original definition based on the income accruing to the child. Section 5 concludes.

\section{An Altruistic Model of Household Behavior}

\subsection{Preferences and the Decision Process}

In our framework, we suppose that a household which comprises an adult $(a)$ and a child (c) makes decisions about consumption. For the moment, our analysis can be seen as

\footnotetext{
${ }^{3}$ See Besley (1990) and Kanbur and Stern (1987) for seminal contributions in targeting theory and Haddad and Kanbur (1992) for an introduction to intra-household targeting.

${ }^{4}$ These benefits correspond to a ration of a certain good that is given or made available below the market price.
} 
restricted to lone parents - which is indeed a relevant focus group for child poverty - but, as is explained below, the results are in fact more general. The consumption is completely private. The $n$-vectors of goods consumed by the adult and the child are denoted by $\boldsymbol{x}^{a}=\left(x_{1}^{a}, \ldots, x_{n}^{a}\right)^{\prime}$ and $\boldsymbol{x}^{c}=\left(x_{1}^{c}, \ldots, x_{n}^{c}\right)^{\prime}$, respectively. The child is egoistic while the adult is altruistic in the sense of Becker, so that her 'total' utility can be written as:

$$
W=U\left[u^{a}\left(\boldsymbol{x}^{a}\right), u^{c}\left(\boldsymbol{x}^{c}\right)\right]
$$

where $u^{a}\left(x^{a}\right)$ is the adult's sub-utility function and $u^{c}\left(x^{c}\right)$ is the child's sub-utility function such as perceived by the adult. The separability of the child's consumption from the adult's one is accepted by the majority of economists, even if not without reservations (Gronau, 1988), and is a crucial component of the welfare analysis that follows. For clarity, however, we use a slightly more restrictive form.

A1. The adult is altruistic in the sense of Becker and her total utility function is given by $W=u^{a}\left(\boldsymbol{x}^{a}\right)+\rho u^{c}\left(\boldsymbol{x}^{c}\right)$.

In the adult's total utility function, $\rho>0$ represents the weight given by the adult to the child. The functions $u^{a}\left(\boldsymbol{x}^{a}\right)$ and $u^{c}\left(\boldsymbol{x}^{c}\right)$ are strictly increasing, strictly concave and twice continuously differentiable in all their arguments.

We suppose that the adult always gets her way. That is, as in Bourguignon (1999), the child is a completely passive member of the household. Formally,

A2. The adult is the effective dictator in the household; she makes decision for her child.

This assumption seems reasonable for investigating economic policies that aim at reducing poverty among young children. This also leaves room for policy intervention if the state believes that the parent's view is wrong: we shall come back to this question. For now, the optimization program can be written as:

$$
\max _{\boldsymbol{x}^{a}, \boldsymbol{x}^{c}} u^{a}\left(\boldsymbol{x}^{a}\right)+\rho u_{c}\left(\boldsymbol{x}^{c}\right) \quad \text { s.t. } \quad \boldsymbol{p}^{\prime}\left(\boldsymbol{x}^{a}+\boldsymbol{x}^{c}\right) \leq Y, \quad \boldsymbol{x}^{a} \geq 0, \quad \boldsymbol{x}^{c} \geq 0
$$

where $\boldsymbol{p}=\left(p_{1}, \ldots, p_{n}\right)^{\prime}$ is the vector of prices and $Y$ is the household total income. Solving first order conditions yields the vector of individual demands for member $g$ :

$$
\boldsymbol{x}^{g}=\boldsymbol{x}^{g}(\boldsymbol{p}, Y) \quad(\text { with } g=a, c) .
$$


These functions are traditional Marshallian demands and thus satisfy the Slutsky condition. Since the optimization program is additively separable, these demands have other properties that will now be examined.

\subsection{Properties of Household Demands}

The separability of the adult's optimization program (2) allows us to proceed with a twostage budgeting interpretation of the decision process. First, income is divided between the adult and the child according to some rule; second, the consumption vectors are chosen as if each individual maximized her own utility subject to her own share of income.

We shall first examine how the intra-household distribution of income is determined. To do so, let $v^{g}\left(\boldsymbol{p}, \phi_{g}\right)$ be the member $g$ 's indirect sub-utility function where $\phi_{g}$ is her share of income. The latter is the solution to:

$$
\max _{\phi_{a}, \phi_{c}} v^{a}\left(\boldsymbol{p}, \phi_{a}\right)+\rho v^{c}\left(\boldsymbol{p}, \phi_{c}\right) \quad \text { s.t. } \quad \phi_{a}+\phi_{c}=Y .
$$

The first order condition of this program is:

$$
\frac{\partial v^{a}}{\partial \phi_{a}}-\rho \frac{\partial v^{c}}{\partial \phi_{c}}=0
$$

Once income is divided between the child and the adult, each of them maximizes her utility subject to her own budget constraint. That is,

$$
\max _{\boldsymbol{x}^{g}} u^{g}\left(\boldsymbol{x}^{g}\right) \quad \text { s.t. } \quad \boldsymbol{p}^{\prime} \boldsymbol{x}^{g} \leq \phi_{g}, \quad \boldsymbol{x}^{g} \geq 0 .
$$

Hence, the individual demands are characterized by the following structure:

$$
\boldsymbol{x}^{g}=\boldsymbol{x}^{g}\left(\boldsymbol{p}, \phi_{g}\right)
$$

where $\boldsymbol{x}^{g}\left(\boldsymbol{p}, \phi_{g}\right)$ is a vector of Marshallian demands, expressed as functions of $\boldsymbol{p}$ and $\phi_{g}$. To simplify notation, let $\phi=\phi_{c}$ and $Y-\phi=\phi_{a}$, where $\phi(\boldsymbol{p}, Y)$ is the 'sharing rule'. This function has properties that we examine below.

\subsubsection{The Effect of Income on the Sharing Rule}

To compute the derivative of the sharing rule with respect to income, we differentiate the first order condition (5) with respect to $Y$ and obtain:

$$
\frac{\partial^{2} v^{a}}{\partial \phi_{a}^{2}}\left(1-\frac{\partial \phi}{\partial Y}\right)-\rho \frac{\partial^{2} v^{c}}{\partial \phi_{c}^{2}} \frac{\partial \phi}{\partial Y}=0
$$


We use the following notation:

$$
\frac{\partial v^{g}}{\partial \phi_{g}}=\lambda_{g}, \quad \frac{\partial^{2} v^{g}}{\partial \phi_{g}^{2}}=\lambda_{g}^{\prime}
$$

noting that $-\lambda_{g}^{\prime} / \lambda_{g}$ is a measure of concavity of member $g$ 's sub-utility. This measure will hereafter be referred to as the income fluctuation aversion of member $g$. Then, using expressions (5) and (7), the effect of income on the sharing rule can be written as:

$$
\frac{\partial \phi}{\partial Y}=\frac{\lambda_{a}^{\prime}}{\lambda_{a}^{\prime}+\rho \lambda_{c}^{\prime}}=-\frac{\lambda_{a}^{\prime} / \lambda_{a}}{\theta} \quad \text { with } \quad \theta=-\left(\frac{\lambda_{a}^{\prime}}{\lambda_{a}}+\frac{\lambda_{c}^{\prime}}{\lambda_{c}}\right)>0 .
$$

Thus this effect is comprised between zero and one: the expenditure devoted to the child is a normal good for the adult. ${ }^{5}$ For each additional unit of income, what is received by the child is the ratio of the adult's aversion to the sum of both members' aversion, i.e., more of the increase of income will accrue to the household member located on the least curve portion of her utility function. Hence, the empirical observation of Blow et al. (2010) that children are insured against fluctuations in income simply means that the child's utility function at the equilibrium point is more concave than that of the adult.

The sum of both members' income fluctuation aversions, denoted above by $\theta$, has an attractive interpretation in terms of complementarity: it corresponds to the derivative of the benevolent parent's marginal rate of substitution, computed at the equilibrium, between the child's allocation $\phi$ and the parent's allocation $Y-\phi$ with respect to the relative implicit prices of child and adult allocations. ${ }^{6}$ In other words, it measures the

\footnotetext{
${ }^{5}$ This is hardly controversial. The normality of the child's welfare, however, is not general but comes from the additivity property of the adult's utility function.

${ }^{6}$ Writing the index maximized by the benevolent parent as: $W=v^{a}\left(\boldsymbol{p}, \phi_{a}\right)+\rho v^{c}\left(\boldsymbol{p}, \phi_{c}\right)$, we compute the marginal rate of substitution between the adult's share and the child's share as:

$$
\left.\frac{\partial \phi_{c}}{\partial \phi_{a}}\right|_{d W=0}=-\frac{\partial v^{a} / \partial \phi_{a}}{\rho \partial v^{c} / \partial \phi_{c}}=-\frac{\lambda_{a}}{\rho \lambda_{c}}
$$
}

The convexity of the benevolent parent's indifference curve with respect to $\phi_{a}$ and $\phi_{c}$ is then given by:

$$
\left.\frac{\partial^{2} \phi_{c}}{\partial \phi_{a}^{2}}\right|_{\mathrm{d} W=0}=-\frac{\lambda_{a}^{\prime}}{\rho \lambda_{c}}-\frac{\lambda_{c}^{\prime} \lambda_{a}^{2}}{\rho^{2} \lambda_{c}^{3}}
$$

and recalling that $\lambda_{a} / \lambda_{c}=\rho$ :

$$
\left.\frac{\partial^{2} \phi_{c}}{\partial \phi_{a}^{2}}\right|_{\mathrm{d} W=0}=-\left(\frac{\lambda_{a}^{\prime}}{\lambda_{a}}+\frac{\lambda_{c}^{\prime}}{\lambda_{c}}\right)=\theta
$$


convexity of the preferences of the benevolent parent regarding allocations $\phi$ and $Y-\phi$. If the latter tend to be perfect substitutes (complements), the indifference curve of the altruistic parent tends to be linear (right-angled) and $\theta$ tends to zero (infinity). The term $\theta$ will thus be referred to as an index of complementarity hereafter.

\subsubsection{The Effect of Prices on the Sharing Rule}

To compute the derivative of the sharing rule with respect to prices, we differentiate the first order condition (5) with respect to $p_{k}$ and obtain:

$$
\left(\frac{\partial^{2} v^{a}}{\partial \phi_{a} \partial p_{k}}-\frac{\partial^{2} v^{a}}{\partial \phi_{a}^{2}} \frac{\partial \phi}{\partial p_{k}}\right)-\rho\left(\frac{\partial^{2} v^{c}}{\partial \phi_{c} \partial p_{k}}+\frac{\partial^{2} v^{c}}{\partial \phi_{c}^{2}} \frac{\partial \phi}{\partial p_{k}}\right)=0 .
$$

From Roy's identity, we have:

$$
\frac{\partial v^{g}}{\partial p_{k}}=-\lambda_{g} x_{k}^{g}, \quad \frac{\partial^{2} v^{g}}{\partial p_{k} \partial \phi_{g}}=-\lambda_{g}^{\prime} x_{k}^{g}-\lambda_{g} \frac{\partial x_{k}^{g}\left(\boldsymbol{p}, \phi_{g}\right)}{\partial \phi_{g}} .
$$

Using these expressions in equation (10) leads to:

$$
\frac{\partial \phi}{\partial p_{k}}=-\frac{1}{\theta}\left[\left(\frac{\lambda_{c}^{\prime}}{\lambda_{c}} x_{k}^{c}-\frac{\lambda_{a}^{\prime}}{\lambda_{a}} x_{k}^{a}\right)+\left(\frac{\partial x_{k}^{c}\left(\boldsymbol{p}, \phi_{c}\right)}{\partial \phi_{c}}-\frac{\partial x_{k}^{a}\left(\boldsymbol{p}, \phi_{a}\right)}{\partial \phi_{a}}\right)\right] .
$$

This expression may be either positive or negative. Now, using expression (9) and simplifying, we obtain:

$$
\frac{\partial \phi}{\partial p_{k}}=x_{k}^{c}-R_{k}-x_{k} \frac{\partial \phi}{\partial Y}
$$

where $x_{k}=x_{k}^{a}+x_{k}^{c}$ and

$$
R_{k}=\frac{1}{\theta}\left(\frac{\partial x_{k}^{c}\left(\boldsymbol{p}, \phi_{c}\right)}{\partial \phi_{c}}-\frac{\partial x_{k}^{a}\left(\boldsymbol{p}, \phi_{a}\right)}{\partial \phi_{a}}\right) .
$$

There are three terms on the right hand side of expression (12). Of course, the last term is a 'conventional' income effect: the child endowment decreases because the real income of the household is reduced by the rise in the price of good $k$. The first two terms play a major role in the derivation of optimal subsidies, and will now be examined.

\subsubsection{Interpretation of $\left(x_{k}^{c}-R_{k}\right)$}

The sum of the first two terms in expression (12) can be seen as a compensated effect of the price $p_{k}$ on the sharing rule. To illustrate this point, let us remark that the sharing 
rule coincides, by definition, with the expenditure made by the household on the child's consumption, that is, $\phi=\sum_{j=1}^{n} p_{j} x_{j}^{c}(\boldsymbol{p}, Y)$. If we differentiate this expression with respect to $p_{k}$, and use the Slutsky equation, we obtain:

$$
\frac{\partial \phi}{\partial p^{k}}=x_{k}^{c}+\sum_{j=1}^{n} p_{j} \omega_{j k}^{c}-\sum_{j=1}^{n} p_{j} \frac{\partial x_{j}^{c}(\boldsymbol{p}, Y)}{\partial Y} x_{k}
$$

where

$$
\omega_{j k}^{c}=\frac{\partial x_{j}^{c}(\boldsymbol{p}, Y)}{\partial p_{k}}+\frac{\partial x_{j}^{c}(\boldsymbol{p}, Y)}{\partial Y} x_{k}
$$

is a traditional substitution term. The last term on the right-hand-side of equation (14) is clearly the income effect described above and the first term is the variation in the sharing rule that maintains the child's utility constant. The second term is thus a moneymetric measure of the variation in the child's utility induced by the price increase when the adult's total utility is maintained constant. The sum of the first two terms is the corresponding compensated effect, that is, the change in the child's share resulting from a simultaneous variation in the price $p_{k}$ and in income $Y$ that keeps the adult's total utility unaffected. Combining these results with expression (12), the term $R_{k}$ can be written as:

$$
R_{k}=-\sum_{j=1}^{n} p_{j} \omega_{j k}^{c} .
$$

and compared to expression (13). It turns out that the sum of the substitution effects weighted by the prices is proportionate to the difference between the child's and the adult's Engel curves. This equivalence stems, as explained by Deaton and Muellbauer (1980), from the separability of the adult's total utility function and can be interpreted as follows. First, remark that the real value of a marginal income unit accruing to a family member depends on the price of the good on which this member tends to spend the income unit: the more expensive this good, the lower the purchasing power of the marginal income unit (Christiansen, 1983). Then, an increase in the price of good $k$ will affect the adult's trade-off between devoting a marginal unit of income to the maximization of her own sub-utility function or to the maximization of that of her child. The price increase will depress both members' purchasing powers, but more so for the child if she has a larger propensity to spend on this good, i.e., if the slope of the Engel curve for good $k$ is steeper for the child than for the adult. This implies a redistribution of resources from the child to the adult. The properties of the sharing rule and the role of the complementarity index are further described in an example based on CARA utility functions in Appendix A. 


\subsubsection{The Effect of Altruism on the Sharing Rule}

For the sake of completeness, we also examine the effect of a change in the child's weight on the sharing rule. To do so, we differentiate the first order condition (5) with respect to $\rho$ and obtain:

$$
\frac{\partial^{2} v^{a}}{\partial \phi_{a}^{2}} \frac{\partial \phi}{\partial \rho}+\frac{\partial v^{c}}{\partial \phi_{c}}+\rho \frac{\partial^{2} v^{c}}{\partial \phi_{c}^{2}} \frac{\partial \phi}{\partial \rho}=0 .
$$

Then, using expressions (8) and (5) gives:

$$
\frac{\partial \phi}{\partial \rho}=-\frac{\lambda_{c}}{\lambda_{a}^{\prime}+\rho \lambda_{c}^{\prime}}=\frac{1}{\theta \rho}>0 .
$$

\subsection{The Case of Two Parents with Opposing Interests}

The present model can be interpreted in a straightforward way as a lone parent with her child. This interpretation alone justifies the study that follows, since single mothers form a particularly relevant focus group with respect to child poverty, and we stick to it in what follows. ${ }^{7}$ However, the model can also represent situations with two adults - provided that slight adjustments are made to the model - and with several children. To show this, let us consider a household with two parents where the mother $(m)$ and the father $(f)$ have an altruistic utility function such as described in A1. If the decision process is supposed to lead to efficient outcomes - according to the so-called collective approach (Browning and Chiappori, 1998; Chiappori and Donni, 2010) - then there exists a bargaining weight $\mu(\boldsymbol{p}, Y)$ such that the household objective function is

$$
W=(1-\mu(\boldsymbol{p}, Y))\left[u^{f}\left(\boldsymbol{x}^{f}\right)+\rho u^{c}\left(\boldsymbol{x}^{c}\right)\right]+\mu(\boldsymbol{p}, Y)\left[u^{m}\left(\boldsymbol{x}^{m}\right)+\rho u^{c}\left(\boldsymbol{x}^{c}\right)\right]
$$

This formulation is completely standard: the bargaining weight $\mu(\boldsymbol{p}, Y)$ represents a power index. If $\mu(\boldsymbol{p}, Y)$ tends to zero the father acts as a dictator in the household and, conversely, if it tends to one, the mother always gets his way. ${ }^{8}$ Using the Hicks-Leontieff

\footnotetext{
${ }^{7}$ Single parents represent around $10 \%$ of all households in the US (13 million households), $14 \%$ in Australia, and a quarter of families with dependent children in the UK, and it should be noted that the relative size of this group is increasing in most countries. Moreover, the prevalence of child poverty is particularly high in this population - see Gornick and Jäntti (2009).

${ }^{8}$ The fact that $\rho$ is the same for the mother and the father is not really important here as individual utility functions can always be linearly transformed.
} 
composite good theorem, the vector of consumption goods $\boldsymbol{x}^{m}$ and $\boldsymbol{x}^{f}$ can be aggregated so that the utility function of the representative adult is ${ }^{9}$

$$
\begin{gathered}
u^{a}\left(\boldsymbol{x}^{a}, \mu(\boldsymbol{p}, Y)\right)=\max _{\boldsymbol{x}^{m}, \boldsymbol{x}^{f}}\left[(1-\mu(\boldsymbol{p}, Y)) u^{f}\left(\boldsymbol{x}^{f}\right)+\mu(\boldsymbol{p}, Y) u^{m}\left(\boldsymbol{x}^{m}\right)\right] \\
\text { s.t. } \boldsymbol{x}^{m}+\boldsymbol{x}^{f}=\boldsymbol{x}^{a} .
\end{gathered}
$$

If this expression is incorporated in (16), the household objective function can be equivalently written:

$$
W=u^{a}\left(\boldsymbol{x}^{a}, \mu(\boldsymbol{p}, Y)\right)+\rho u^{c}\left(\boldsymbol{x}^{c}\right) .
$$

The total utility function of the adult is the same as that given in A1 except that the representative adult's utility also depends on prices and income through the bargaining function. ${ }^{10}$ The comparative statics analysis of the preceding section thus remains valid on the condition that the function $\mu(\boldsymbol{p}, Y)$ is actually a constant. This is the case in traditional representations of multi-person households such as the Rotten Kid model (Becker 1974) and the Consensus model (Samuelson, 1956). More generally, it is sufficient to suppose that the function $\mu(\boldsymbol{p}, Y)$ does not depend on the price of the good on which the subsidy is placed (the other prices remaining constant in our analysis). Indeed, if $\mu(\boldsymbol{p}, Y)$ is independent of $p_{k}$, it can easily be shown (computations are left to the reader) that the effect of the price of good $k$ on the sharing rule is simply given by

$$
\frac{\partial \phi}{\partial p_{k}}=x_{k}^{c}-R_{k}-\left.x_{k} \frac{\partial \phi}{\partial Y}\right|_{\mathrm{d} \mu=0},
$$

where $\partial \phi /\left.\partial Y\right|_{\mathrm{d} \mu=0}$ is the effect of income on the sharing rule when $\mu$ is maintained constant. ${ }^{11}$ In general, the exclusion of the price of the subsidized good from the arguments of the bargaining function is not an excessively restrictive assumption. In bargaining models of household behavior à la Manser and Brown (1980) and McElroy and Horney (1981) for instance, the spouses' bargaining position in the couple is determined by the level of

\footnotetext{
${ }^{9}$ If there are several children, it would be possible to aggregate individual child's utility functions.

${ }^{10}$ Dauphin et al. (2011) consider a more general model of household behavior where children have a say in decisions. In that case, children are characterized by specific bargaining weights that depend on prices and income. This is not our approach here because, as explained above, we focus on young children.

${ }^{11}$ If the function $\mu(\boldsymbol{p}, Y)$ do depend on the price of good $k$, then an additional term will enter the derivative of the sharing rule (17), the sign of which is a priori undetermined. This term represents the effect of the price of good $k$ channeled through the function $\mu(\boldsymbol{p}, Y)$.
} 
utility that they can obtain when divorce is involved. Unless the effect of the price of the subsidized good on welfare is very different for each divorced spouse, it can be supposed at least as an approximation that this price does not affect the bargaining function. ${ }^{12}$

\section{Price Subsidies and Cash Transfers: Impact on Child Welfare}

\subsection{Variations in Child Welfare}

In the present section, we examine the marginal impact of price subsidies on child welfare in a representative household. This is in line with our initial objective of studying the targeting of specific individuals within the families. ${ }^{13}$ Since the objective of the planner is to improve the child's well-being, we concentrate on the marginal impact of price subsidies, simply defined as a reduction in the free market price of one good. Yet the analysis can be readily extended to the marginal impact of taxes (which is simply the opposite), also of great empirical relevance. We then suppose that the planner's anticipation of the child welfare coincides with that of the adult. This assumption is relaxed later on. Moreover, the analysis is partial in the sense that producer prices are constant. One natural interpretation is that prices are determined by world markets.

To begin with we define a unidimensional measure of the variation in the child's standard of living. The Hicksian variation $-\mathrm{dV}$ (with a negative sign for convenience) that compensates the child for an infinitesimal variation in prices $\mathrm{d} \boldsymbol{p}$ and income $\mathrm{d} Y$ is defined implicitly by:

$$
\mathrm{d} v^{c}=\sum_{j=1}^{n}\left(\frac{\partial v^{c}}{\partial p_{j}}+\frac{\partial v^{c}}{\partial \phi_{c}} \frac{\partial \phi}{\partial p_{j}}\right) \mathrm{d} p_{j}+\frac{\partial v^{c}}{\partial \phi_{c}} \frac{\partial \phi}{\partial Y} \mathrm{~d} Y-\frac{\partial v^{c}}{\partial \phi_{c}} \mathrm{dV}=0 .
$$

\footnotetext{
${ }^{12}$ One important exception concerns the price of leisure. Indeed it is clear that wage rates significantly affect the after-divorce situation of peoples. Hence it must also influence their bargaining position before divorce. This is confirmed by empirical studies that show that the spouses' relative earnings capacity affect the structure of consumption of married couples; see Lundberg et alii (1997) for instance. Therefore leisure must be excluded from the goods that can be considered in our analysis.

${ }^{13}$ We do not follow the path of optimal taxation whereby the social planner maximizes a convex combination of parent's and child's welfare indices. By focusing on child welfare, we follow the literature on targeting as explained in the introduction.
} 
As is usual, the opposite of the Hicksian variation can be interpreted as a monetary measure of the variation in child's well-being. Its explicit form is written:

$$
\mathrm{dV}=\sum_{j=1}^{n}\left(\frac{\partial v^{c} / \partial p_{j}}{\partial v^{c} / \partial \phi_{c}}+\frac{\partial \phi}{\partial p_{j}}\right) \mathrm{d} p_{j}+\frac{\partial \phi}{\partial Y} \mathrm{~d} Y
$$

\subsection{The Marginal Impact of Taxes/Subsidies}

The first question is then to determine whether a marginal increment of the subsidy actually improves the child's welfare and, if so, by how much. To do so, we assume that each unity of good $k$ is subsidized at a constant rate. Hence $\mathrm{d} s_{k}=-\mathrm{d} p_{k}>0$ where $s_{k}$ is the subsidy placed on good $k$. Thus, if we use expression (18) and the Roy's identity, substituting expression (12) for the derivative of the sharing rule, we obtain the marginal impact of the subsidy on cash-equivalent welfare:

$$
\mathrm{d} \mathrm{V}=\left(x_{k} \frac{\partial \phi}{\partial Y}+R_{k}\right) \cdot \mathrm{d} s_{k}
$$

The first term in this expression, $x_{k}(\partial \phi / \partial Y)$, is positive. This is the traditional income effect described above. The second term, $R_{k}$, represents the distortions generated by the subsidy and expected to be favorable to the child. As defined in equation (13), it is equal to the inverse of the complementarity index multiplied by the difference in the slopes of the Engel curves. Specifically, the subsidy will be very effective (i) if the complementarity index is small, i.e., there is some substitutability between the child's and the adult's welfares, and (ii) if the slope of the Engel curve of the child is very steep in comparison with that of the adult (and, in particular, if good $k$ is superior and exclusively consumed by the child). On the contrary, if the slope of the Engel curve of the adult is large by comparison with that of the child, the subsidy will generate 'bad' distortions and may lead to a reduction in the child's well-being. Henceforth, the term $R_{k}$ will be referred to as the redistributive or targeting effect of the subsidy.

To evaluate the effectiveness of the subsidy, we have to compute its marginal impact per unit spent by the planner. If some goods $j(\neq k)$ consumed by the household are taxed (or subsidized), the marginal cost of the subsidy on good $k$ will incorporate the change in tax revenue due to the rise in the subsidy. More precisely, let us denote fiscal

revenue as $\sum_{j=1}^{K} t_{j} x_{j}-s_{k} x_{k}$, where $t_{j}$ is the tax rate on good $j$, so that good $k$ can be 
subsidized and taxed simultaneously. The marginal cost of the subsidy is then given by:

$$
\mathrm{d} B=\left[\left(x_{k}-s_{k} \frac{\partial x_{k}(\boldsymbol{p}, Y)}{\partial p_{k}}\right)+\left(\sum_{j=1}^{K} t_{j} \frac{\partial x_{j}(\boldsymbol{p}, Y)}{\partial p_{k}}\right)\right] \cdot \mathrm{d} s_{k} .
$$

The first term in parentheses is positive, in principle, while the second term may be positive or negative depending on whether the taxed goods are, on the whole, gross substitutes or complements of the subsidized good. Overall, it is even possible that the marginal cost of the subsidy is negative if tax rates on the complements of the subsidized good are particularly high. ${ }^{14}$ To make the interpretation of the results easier, however, we can suppose that the goods consumed by the household are not taxed. ${ }^{15}$

A3. The goods are not taxed before the introduction of the subsidy, i.e., $t_{j}=0$ for $j=1, \ldots, K$, and the marginal cost of the subsidy is strictly positive, i.e.,

$$
x_{k}-s_{k} \frac{\partial x_{k}(\boldsymbol{p}, Y)}{\partial p_{k}}>0 .
$$

The marginal cost of the subsidy is positive if good $k$ is not a Giffen good and its consumption is positive. Thus, the marginal impact in terms of child's welfare per unit of public budget is given by:

$$
\mathrm{dV}=\left(x_{k} \frac{\partial \phi}{\partial Y}+R_{k}\right)\left(x_{k}-s_{k} \frac{\partial x_{k}(\boldsymbol{p}, Y)}{\partial p_{k}}\right)^{-1} \cdot \mathrm{d} B
$$

To gain insight into this rule, we compute the marginal welfare gain per budget unit at the no-subsidy situation, i.e., when $s_{k}=0$, and obtain:

$$
\mathrm{dV}=\left(\frac{\partial \phi}{\partial Y}+\frac{R_{k}}{x_{k}}\right) \cdot \mathrm{d} B
$$

Using the definition of $R_{k}$, this expression offers a simple optimal rule for the practitioner who wants to improve children's welfare.

\footnotetext{
${ }^{14}$ There is one argument - not completely satisfactory - which is in favor of the complementarity hypothesis. Let us suppose that tax rates are proportionate to prices, i.e., $t_{j}=\tau p_{j}$ for some scalar $\tau$. Hence, $\sum_{j=1}^{K} t_{j} \partial x_{j}(\boldsymbol{p}, Y) / \partial p_{k}=\tau \sum_{j=1}^{K} p_{j} \partial x_{j}(\boldsymbol{p}, Y) / \partial p_{k}=-\tau x_{k}$ from the Cournot aggregation condition. The marginal cost of the subsidy is thus reduced accordingly.

${ }^{15}$ Alternatively, we can suppose that the derivative of the demands for the taxed goods with respect to the price of good $k$ is equal to zero.
} 
Proposition 1 Assume A1-A3. Then, starting from the no-subsidy situation, a subsidy will be most effective in improving child welfare when put on the good for which the difference between the slope of the Engel curve of the child and that of the adult, divided by the level of consumption, is the largest.

\subsection{The Income Elasticity Rule}

To implement these results, the planner must have information about the slopes of the Engel curves. The identification of these curves for goods consumed by both the parent and the child from cross-sectional data is complicated but not impossible (as discussed in the conclusion). To make things easier, however, we consider hereafter subsidizing a good which is exclusively consumed by the child. This is a desirable situation since the targeting effect is necessarily positive (at least if the exclusive good is normal). Thus, if good $k$ is specific to children, the effect of income on demand can be written as:

$$
\frac{\partial x_{k}(\boldsymbol{p}, Y)}{\partial Y}=\frac{\partial x_{k}^{c}\left(\boldsymbol{p}, \phi_{c}\right)}{\partial \phi_{c}} \frac{\partial \phi}{\partial Y} \quad \text { and thus: } \quad \frac{\partial x_{k}^{c}\left(\boldsymbol{p}, \phi_{c}\right)}{\partial \phi_{c}}=\frac{\partial x_{k}(\boldsymbol{p}, Y)}{\partial Y} / \frac{\partial \phi}{\partial Y} .
$$

Substituting the value (22) for the slope in the marginal impact (21) leads to the following proposition.

Proposition 2 (Income Elasticity Rule) Assume A1-A3 and assume that goods $j$ and $k$ are exclusively consumed by the child. Then, starting from the no-subsidy situation, a subsidy will be more effective in improving child welfare when placed on good $k$ rather than on good $j$ if and only if

$$
\frac{Y}{x_{k}} \frac{\partial x_{k}(\boldsymbol{p}, Y)}{\partial Y}>\frac{Y}{x_{j}} \frac{\partial x_{j}(\boldsymbol{p}, Y)}{\partial Y},
$$

i.e., the income elasticity of good $k$ is greater than that of good $j$.

The planner has thus a simple way to select empirically the 'child-specific' good for which the subsidy will have the largest effect. The intuition is simple. If the income elasticity of the subsidized good is close to zero, the subsidy will not generate 'good' distortions (that are channeled by the intra-household redistribution of income) and its impact will be comparable to that of a cash transfer. On the contrary, if the income elasticity is positive and large, the subsidy will generate favorable distortions and induce the adult to purchase a larger quantity of the subsidized good. 
The nature of the (child) goods to be targeted is an open empirical question. In the introduction, we gave several examples of price subsidies on children's clothing, nappies, dairy products, child furniture and school equipment in operation in several countries. In the empirical literature, and because of lack of appropriate data, there is little evidence on the income elasticities of various child goods. One exception is the semiparametric estimation of Engel curves for rural Pakistan in Bhalotra and Attfield (1998) who report that child goods, including children's furniture and nursery items, toys, children's footwear and pocket money, are luxuries until the very edge of the income range in their sample. The present paper shows that these goods are of interest because it is possible to redistribute towards children thanks to targeted price subsidies.

\subsection{Price Subsidies versus Cash Transfers}

We now suppose that the planner has the possibility to use lump-sum transfers, such as child benefits, as an additional instrument. The main feature of such transfers is that they are not associated with dead weight loss. We thus question whether the increment in the price subsidy is dominated by a similar increment in a lump-sum transfer when the government aims to improve child welfare. To examine this issue, we suppose that $\mathrm{d} Y=$ $\mathrm{d} T>0$ where $T$ is the cash transfer. This way, the marginal impact of the transfer on the child's welfare is equal to:

$$
\mathrm{dV}=\frac{\partial \phi}{\partial Y} \cdot \mathrm{d} T
$$

The effectiveness of the lump-sum transfer is thus reduced by the fact that the derivative of the sharing rule is less than one.

Proposition 3 Assume A1-A3. Then, for the same marginal increase in public budget, the welfare impact of a subsidy placed on good $k$ is larger than that of a cash transfer if

$$
\frac{\partial \phi}{\partial Y} \frac{\partial x_{k}(\boldsymbol{p}, Y)}{\partial p_{k}} s_{k}+R_{k} \geq 0 .
$$

To see this result, we establish the difference between the welfare gain of the subsidy and that of the cash transfer for a comparable marginal increase in public budget, i.e., $\Delta=\partial \mathrm{V} / \partial B-\partial \mathrm{V} / \partial T$. Then, using expressions (20) and (23) to simplify this expression and using A3, we consider the case when $\Delta$ is positive and obtain condition (24). The first 
term represents the tax leakage of the subsidy (i.e., the difference between the effect of a marginal increase in the subsidy on the household real income, $x_{k}$, and its effect on the budget of the planner, $\left.x_{k}-s_{k} \partial x_{k}(\boldsymbol{p}, Y) / \partial p_{k}\right)$ multiplied by the derivative of the sharing rule, i.e., the proportion of the tax leakage supported by the child. This is not surprising because, as is well-known, the welfare cost of a fiscal reform that modifies marginal tax rates and returns the money to the household as a cash transfer is equal to the tax leakage (Allgood and Snow, 1998). The first term is in principle negative but counteracted by the second term, the targeting effect. As seen before, the sign of the latter depends on the difference between the slopes of child's and adult's Engel curves. Interestingly, in the no-subsidy situation, the first term vanishes so that the marginal increase in the subsidy has purely a targeting effect.

Proposition 4 Assume A1-A3. Then, starting from the no-subsidy situation, a subsidy placed on a good will be more effective in improving child welfare than a cash transfer if the targeting effect of this good is positive.

The conclusion is that a subsidy placed on 'well-chosen' goods, i.e., goods with large targeting effects, always has the potential to dominate cash transfers.

Another message from condition (24) is that there is no opportunity for intra-household targeting through the channel of the price structure if all the individual demands possess linear Engel curves with common slopes across household members. In this case, the effect of a subsidy would be equivalent to that of a cash transfer. This is reminiscent of a result by Deaton (1979) which determines under which conditions a system of differential taxes can be optimal to attain redistributive objectives. The intuition behind this result is that the preferences obey the Gorman polar form (Gorman, 1953) required for exact aggregation of commodity demands. If such aggregation is possible, then we cannot use variations in prices to distinguish among individual for purposes of redistribution.

The introduction of a subsidy will be more favorable to children than that of a cash transfer up to the point where expression (24) is equal to zero, which defines an upper threshold $s_{k}^{*}$ for the subsidy:

$$
\frac{s_{k}^{*}}{p_{k}}=-\left(\frac{\partial \phi}{\partial Y}\right)^{-1}\left(\frac{p_{k}}{x_{k}} \frac{\partial x_{k}(\boldsymbol{p}, Y)}{\partial p_{k}}\right)^{-1} \frac{R_{k}}{x_{k}} .
$$

The subsidy will be more effective than the transfer as long as $s_{k}<s_{k}^{*}$, i.e., the optimal subsidy rate. The optimal subsidy rate on good $k$ is inversely related to its own price 
elasticity and positively related to the targeting effect divided by $x_{k}$. If the planner assigns a budget $B$ to improve child welfare, the optimal policy mix thus consists in setting the subsidy on good $k$ to $s_{k}^{*}$ and distributing the rest of the public budget, $B-s_{k}^{*} x_{k}$, as child benefit (or, of course, placing a subsidy on other goods).

\subsection{Additional Arguments}

We present here two specific arguments in favor of either price subsidies or cash transfers.

\subsubsection{Paternalism and (De)merit Goods}

A specific effect in favor of price subsidies may occur when the government judges that the preferences used by the adult to determine the child's needs are a 'faulty' representation of the child's well-being. In that case, the planner will have the objective to modify the structure of the child's consumption and not only its level. To examine this form of paternalism, we then follow Besley's (1988) approach to (de)merit goods. ${ }^{16}$ That is to say, we suppose that the planner values the child's consumption differently from the adult and treats the child as having utility defined by:

$$
\bar{u}^{c}\left(\boldsymbol{x}^{c}\right)=u^{c}\left(\overline{\boldsymbol{x}}^{c}\right)
$$

with $\overline{\boldsymbol{x}}^{c}=\boldsymbol{\delta} \odot \boldsymbol{x}^{c}$ where $\boldsymbol{\delta}=\left(\delta_{1}, \ldots, \delta_{n}\right)^{\prime}$ is a vector of positive constants and $\odot$ is the Hadamard product (i.e., the element-by-element product). This representation is intuitive. If we suppose that all the $\delta$ 's are equal to one except that of good $k$-in other words, governments do respect the choices that the adult make for all the goods except one -, we can classify good $k$ as a merit good if $\delta_{k}>1$ and a demerit good if $\delta_{k}<1$.

With this specification, the adult behaves as if she maximized the planner's representation of the child's utility function, though without perceiving the true system of prices and the true sharing rule. That is, she over-estimates the price of the merit goods and under-estimates the price of the demerit goods. The system of demand equations is:

$$
\boldsymbol{x}^{c}\left(\boldsymbol{p}, \phi_{c}\right)=\overline{\boldsymbol{x}}^{c}\left(\overline{\boldsymbol{p}}, \bar{\phi}_{c}\right),
$$

\footnotetext{
${ }^{16}$ In what follows, the merit of the good can be the result of externalities in consumption, lack of information, community values and so on. See Musgrave (1987) for a definition of merit goods.
} 
where $\overline{\boldsymbol{x}}^{c}(\cdot)$ is the Marshallian demand functions obtained from the planner's representation of child's utility $\bar{u}^{c}\left(\boldsymbol{x}^{c}\right), \overline{\boldsymbol{p}}=\boldsymbol{\delta} \odot \boldsymbol{p}$ are the shadow prices of goods and

$$
\bar{\phi}_{c}=\phi_{c}+(\overline{\boldsymbol{p}}-\boldsymbol{p})^{\prime} \boldsymbol{x}^{c}\left(\boldsymbol{p}, \phi_{c}\right)
$$

is the shadow share of income. In Appendix B, it is shown that the marginal impact associated with the subsidy rise is:

$$
\mathrm{dV}=\left[x_{k} \frac{\partial \phi}{\partial Y}+\left(R_{k}+P_{k}\right)\right] \cdot \mathrm{d} s_{k}
$$

where

$$
P_{k}=\delta_{k} \sum_{j=1}^{N} p_{j}\left(1-\delta_{j}\right) \bar{\sigma}_{j k} \quad \text { and } \quad \bar{\sigma}_{j k}=\frac{\partial \bar{x}_{c}^{j}\left(\overline{\boldsymbol{p}}_{\bar{\phi}} \bar{\phi}_{c}\right)}{\partial \bar{p}_{k}}+x_{k}^{c} \frac{\partial \bar{x}_{c}^{j}\left(\overline{\boldsymbol{p}}, \bar{\phi}_{c}\right)}{\partial \bar{\phi}_{c}}
$$

that is, the marginal impact includes a new term $P_{k}$ which represents the paternalistic effect of the subsidy. Following the same argument as in section 3.4, it is now possible to present the condition under which a price subsidy dominates a cash transfer:

$$
\frac{\partial \phi}{\partial Y} \frac{\partial x_{k}(\boldsymbol{p}, Y)}{\partial p_{k}} s_{k}+\left(R_{k}+P_{k}\right) \geq 0
$$

To interpret this expression, let us suppose that all the $\delta$ 's are equal to one except that of good $k$. The paternalistic effect boils down to $P_{k}=\delta_{k} p_{k}\left(1-\delta_{k}\right) \bar{\sigma}_{k k}$. This term is positive - and reinforces the targeting effect in condition (29) - if good $k$ is a merit good, and negative if good $k$ is a demerit good. Alternatively, let us suppose that all the $\delta$ 's are equal to one except that of some good $j$ (different from good $k$ ). The paternalistic effect becomes $P_{k}=\delta_{k} p_{j}\left(1-\delta_{j}\right) \bar{\sigma}_{j k}$. The sign of this term depends on whether goods $k$ and $j$ are substitutes or complements. In particular, if goods $k$ and $j$ are substitutes (complements), the paternalistic effect is negative (positive) for a merit good and positive (negative) for a demerit good. To summarize this discussion, let us say that price subsidies are particularly effective (by comparison with cash transfers) when placed on merit goods or on goods which are complementary to some merit goods.

\subsubsection{Two Parents with Conflicting Interests}

The case of two parents with diverging views was ignored up to this point. To discuss this extension, let us suppose that $\mu(p, Y)$ does not depend on $p_{k}$ as is explained above. 
In that simplified case, it is easy to show, from expression (17), that the welfare effect of an increase in the subsidy is simply given by

$$
\mathrm{dV}=\left(\left.x_{k} \frac{\partial \phi}{\partial Y}\right|_{\mathrm{d} \mu=0}+R_{k}\right) \cdot \mathrm{d} s_{k}
$$

which is similar to expression (19) with $\partial \phi /\left.\partial Y\right|_{\mathrm{d} \mu=0}$ instead of $\partial \phi / \partial Y$. In addition, the conclusions of Proposition 1 and 2 are not modified. Nonetheless, the condition under which price subsidies dominate cash transfers becomes:

$$
\frac{\partial \phi}{\partial Y} \frac{\partial x_{k}(\boldsymbol{p}, Y)}{\partial p_{k}} s_{k}+R_{k}-x_{k}\left(\frac{\partial \phi}{\partial Y}-\left.\frac{\partial \phi}{\partial Y}\right|_{\mathrm{d} \mu=0}\right) \geq 0 .
$$

Hence a third term enters the condition above and modifies the previous conclusions. The term in parentheses can alternatively be written as:

$$
\frac{\partial \phi}{\partial Y}-\left.\frac{\partial \phi}{\partial Y}\right|_{\mathrm{d} \mu=0}=\frac{\partial \phi}{\partial \mu} \times \frac{\partial \mu}{\partial Y} .
$$

Intuitively, the right-hand side of this expression will be positive if an increase in household income improves the mother's bargaining power and if the increase in bargaining power has a positive impact on the child's share of income - the latter assumption is usual, if not uncontroversial. In that case, cash transfers may have a particularly strong impact on the child's welfare and dominate price subsidies even when $s_{k}$ is close to zero. There is no clear evidence that $\partial \mu / \partial Y$ is positive, though. Maybe the most interesting case is when the bargaining weight has both spouses' incomes as specific arguments, that is, $\mu=\mu\left(\boldsymbol{p}, Y_{m}, Y_{f}\right)$ where $Y_{m}$ and $Y_{f}$ represent the mother's and father's incomes respectively (with $Y_{m}+Y_{f}=Y$ ). It seems natural to suppose that $\partial \mu / \partial Y_{m}>0$ and $\partial \mu / \partial Y_{f}<0$, so that the effect of a cash transfer on the child's welfare depends on who is the recipient of the transfer. More precisely, if the transfer is paid to women, then its effectiveness is strengthened while, if the transfer is paid to men, it is weakened. ${ }^{17}$

\footnotetext{
${ }^{17}$ Related to this is the notion of labeling according to which transfers labeled as child benefit are spent disproportionately more on child goods than other incomes. Indeed recipients may use different mental accounts for different expenditure categories, a phenomenon which limits the fungibility of income and constraints consumption patterns in certain ways (Thaler, 1999). If the labeling effect is positive, the superiority of the price subsidy is more difficult to reach. Regarding this issue, empirical results are mixed. Some studies find indeed a significant labeling effect (Kooreman, 2000, Madden, 1999) while others do not (Edmonds, 2002).
} 


\section{Application: Targeting Child Poverty}

\subsection{An Original Definition of Child Poverty}

An obvious application of the previous results is the study of child poverty. The usual practice assumes that a poor child is one living in a poor household (e.g., a household with income below $50 \%$ of the median). However, whether this is the case or not depends on how income is shared within the household. Interestingly, the present framework allows defining child poverty directly in reference to the level of household resources accruing to the child, i.e., her share $\phi(\boldsymbol{p}, Y) .{ }^{18}$ Child poverty will coincide with household poverty, measured on the basis of household income $Y$, only when $\phi$ is a linear function of $Y$.

In the literature on targeting, cash transfers are often preferred to price subsidies. The former are indeed identical for all households while the gain due to a subsidy depends on the consumption level of that good. If the good is normal, the subsidy will benefit more to rich households and miss its target. This idea is presented by Besley and Kanbur (1988). Our framework, however, provides an additional argument in favor of subsidies when policies are used to tackle child poverty. To show this, we first assume the following.

A4. In the population, households differ only with respect to the income level $Y$ and $f(Y)$ is the (well behaved) density function of household income.

We posit a poverty line $z_{c}$ so that children with $\phi(\boldsymbol{p}, Y) \leqslant z_{c}$ are classified as being in poverty. Since the function $\phi$ is monotonically increasing in $Y$, there exists a value $Z_{c}$ representing the level of household income at the child poverty line and implicitly defined by $z_{c}=\phi\left(\boldsymbol{p}, Z_{c}\right)$. As argued above, $Z_{c}$ does not necessarily give a poverty line for the household as a whole or for the adult. The proportion of poor children is given by: $H=\int_{0}^{Z_{c}} f(Y) \cdot \mathrm{d} Y$. To aggregate information on units below the poverty line, we make use of the income gap measure of poverty, defined as:

$$
P=\int_{0}^{Z_{c}}\left(\frac{z_{c}-\phi(p, Y)}{z_{c}}\right) f(Y) \cdot \mathrm{d} Y .
$$

For our present concerns, this approach is very simple and convenient, even if insensitive to the distribution of income among poor children. Further extensions could look at the

\footnotetext{
${ }^{18}$ Quite intuitively, the adult's expenses devoted to children are all the more dispersed - and the poverty important - as the children's aversion to income fluctuation is large.
} 
results when using alternative measures of poverty.

In the following, we assume that the government targets redistributive policies at households with income below $Z_{a}>Z_{c}$. That is, only the $Z_{a}$-population will benefit from the subsidy or the cash transfer. The proportion of households belonging to this population is given by: $G=\int_{0}^{Z_{a}} f(Y) \cdot \mathrm{d} Y$. In practice, the choice of the means-test level $Z_{a}$ will depend on the information available on household incomes and children costs. We consider two polar cases in the sequel: (i) the government is able to identify and target households containing poor children as previously defined, i.e., $Z_{a}=Z_{c}$; (ii) income test is not possible or not desirable and both cash transfers and price subsidies are universal, i.e., $Z_{a}$ corresponds to the highest income in the population.

\subsection{Marginal Impacts of Subsidies and Transfers}

First, the budgetary cost of a subsidy on good $k$ is simply:

$$
B=\int_{0}^{Z_{a}} s_{k} x_{k}(\boldsymbol{p}, Y) f(Y) \cdot \mathrm{d} Y,
$$

so that

$$
\frac{\partial B}{\partial s_{k}}=\int_{0}^{Z_{a}}\left(x_{k}(\boldsymbol{p}, Y)-s_{k} \frac{\partial x_{k}(\boldsymbol{p}, Y)}{\partial p_{k}}\right) f(Y) \cdot \mathrm{d} Y
$$

or

$$
\frac{\partial B}{\partial s_{k}}=G\left[E_{a}\left(x_{k}\right)-s_{k} E_{a}\left(\frac{\partial x_{k}}{\partial p_{k}}\right)\right]
$$

where

$$
E_{a}\left(x_{k}\right)=\frac{1}{G} \int_{0}^{Z_{a}} x_{k}(\boldsymbol{p}, Y) f(Y) \cdot \mathrm{d} Y, \quad E_{a}\left(\frac{\partial x_{k}}{\partial p_{k}}\right)=\frac{1}{G} \int_{0}^{Z_{a}} \frac{\partial x_{k}(\boldsymbol{p}, Y)}{\partial p_{k}} f(Y) \cdot \mathrm{d} Y
$$

are the demand for good $k$ and its derivative averaged over the $Z_{a}$-population. The derivative (31) will be positive if A3 holds for all the households.

We then investigate the effect on the child poverty measure of a marginal increment in the budget due to a subsidy on good $k$. That is,

$$
\frac{\partial P}{\partial B}=-\frac{1}{z_{c}}\left(\int_{0}^{Z_{c}} \frac{\partial \mathrm{V}}{\partial B} \cdot f(Y) \cdot \mathrm{d} Y\right)
$$

or, using the values for $\partial \mathrm{V} / \partial B$,

$$
\frac{\partial P}{\partial B}=-\frac{1}{z_{c}} \times \frac{H}{G} \times\left[E_{c}\left(x_{k} \frac{\partial \phi}{\partial Y}\right)+E_{c}\left(R_{k}\right)\right] \times\left[E_{a}\left(x_{k}\right)-s_{k} E_{a}\left(\frac{\partial x_{k}}{\partial p_{k}}\right)\right]^{-1}
$$


where

$$
E_{c}\left(x_{k} \frac{\partial \phi}{\partial Y}\right)=\frac{1}{H} \int_{0}^{Z_{c}} x_{k}(\boldsymbol{p}, Y) \frac{\partial \phi}{\partial Y} f(Y) \cdot \mathrm{d} Y, \quad E_{c}\left(R_{k}\right)=\frac{1}{H} \int_{0}^{Z_{c}} R_{k} f(Y) \cdot \mathrm{d} Y
$$

are the income effect and the targeting effect of the subsidy, averaged over the $Z_{c}-$ population of households with a child in poverty. The interpretation of this expression is analogous to that of expression (20).

For the sake of comparison, we also measure the marginal impact of a lump-sum transfer, that is,

$$
\frac{\partial P}{\partial T}=-\frac{1}{z_{c}} \times \frac{H}{G} \times E_{c}\left(\frac{\partial \phi}{\partial Y}\right)
$$

where

$$
E_{c}\left(\frac{\partial \phi}{\partial Y}\right)=\frac{1}{H} \int_{0}^{Z_{c}} \frac{\partial \phi}{\partial Y} f(Y) \cdot \mathrm{d} Y .
$$

Using these expressions, it is easy to derive the condition under which $\Delta=\partial P / \partial B-$ $\partial P / \partial T$ is negative. This leads to the analogue of Proposition 3.

Proposition 5 Assume A1-A4. Then, for the same marginal increase in public budget, a subsidy placed on good $k$ is more effective than a cash transfer in reducing (the income gap measure of) child poverty if

$$
s_{k} E_{c}\left(\frac{\partial \phi}{\partial Y}\right) E_{a}\left(\frac{\partial x_{k}}{\partial p_{k}}\right)+E_{c}\left(R_{k}\right)+\left[E_{c}\left(x_{k} \frac{\partial \phi}{\partial Y}\right)-E_{a}\left(x_{k}\right) E_{c}\left(\frac{\partial \phi}{\partial Y}\right)\right]>0 .
$$

The first two terms are close to those in (24) while the last term resembles that in Besley and Kanbur (1988). The first term, corresponding to the tax leakage of the price distortion, is negative but may be set arbitrarily small. The second term is always positive for (normal) child-specific goods. The last term, in square brackets, will generally be negative if there is no means-test. It will be all the smaller in terms of absolute value as we move from universal to means-tested instruments. To show this, let us assume that $\partial \phi / \partial Y$ is independent of $x_{k}$ and then write the last term as:

$$
E_{c}\left(\frac{\partial \phi}{\partial Y}\right) \times\left[E_{c}\left(x_{k}\right)-E_{a}\left(x_{k}\right)\right] .
$$

If both instruments are universal, i.e., $E_{a}$ is the average over the whole population, this expression is certainly negative since the mean consumption in families with poor children 
is less than the mean consumption in the population. In this case, the targeting effect of price subsidies must be strong for condition (34) to be respected. On the other hand, the means-test of redistributive policies, as often implemented in developed countries, may considerably reduce the size of the third term. In the extreme case where the means-test allows a perfect targeting at poor children, i.e., if $Z_{a}=Z_{c}$, this last term is null and the price subsidy is unambiguously preferred. In Appendix A, an illustration with the CARA utility function is given.

One last remark is in order. Other forms of household heterogeneity can be incorporated to explain the dispersion of the child's share of income. Nonetheless, the main conclusions here are not altered as far as heterogeneity can be represented by a unidimensional scalar $\nu$ which is monotonic in the sense that, if $\nu_{0}$ is smaller than some value $\nu_{1}$, then $\phi\left(\boldsymbol{p}, Y, \nu_{0}\right)<\phi\left(\boldsymbol{p}, Y, \nu_{1}\right)$. For instance, let us suppose that heterogeneity stems from the parameter $\rho$ - the density function of which is given by $f(\rho)$ - that represents the degree of parent's altruism. The monotonicity condition is satisfied here because of inequality (15). Then it is possible to define a poverty line $Z_{c}$ such that for all the households with $\rho<Z_{c}$, children will be in poverty. Following the same line of reasoning as above, we can see that the condition (34) is still valid. The main difference is that altruism is more difficult to observe; hence universal policies are easier to implement.

\section{Conclusion}

Using a general representation of households with children, we study the relative merits of price subsidies and cash transfers in targeting child welfare. We show that the effect of price subsidies on child welfare can be broken down in, at least, an income effect and a 'targeting effect'. For any particular good, the latter affects child welfare positively if, and all the more so as, the slope of the Engel curve for the child is larger than that of the adult. It comes that if the tax leakage of the subsidy is small enough compared to this targeting effect, price subsidies dominate cash transfers. Child exclusive goods always have positive targeting effects. Importantly, the effectiveness of a subsidy (or a tax) as a targeting device depends on the responsiveness of individual consumptions to variations in income. In addition, we have extended these results to the problem of poverty alleviation in a continuum of households (with heterogeneity in income). In particular, the reduction 
in child poverty may be larger using well-chosen subsidies rather than cash transfers if child poverty is high and the parents' propensity to devote income to children is small.

We believe that the present framework is an original attempt to characterize policies aimed at targeting certain individuals within the household. With the suggested model, it becomes possible to assess the relative cost efficiency of indirect taxes and, more generally, most policy instruments that combine price and income effects to alleviate child poverty. Naturally, future work should overcome some of the primary limitations of this contribution. Firstly, the production side has been ignored in our partial equilibrium analysis. If the supply of subsidized goods is rigid, its price will increase as a reaction to the introduction of the subsidy, canceling distortions but also the targeting effect. Secondly, our analysis has considered only private goods, while the level of public consumption achieved by the household can be crucial for the welfare of children. Measures of material deprivation often include public durable goods. Nonetheless, it is possible to extend the present model to public goods, as done in the collective model literature (Donni, 2009), or very simply using Barten technology parameters to represent joint consumption (Browning et al., 2006). Finally, we indicate in the text how results may vary when households differ not with income but with the degree of parent's altruism - more work is however required to introduce multi-dimensional heterogeneity.

Our concluding words concern the empirical implementation of the theoretical tools developed in this paper. The components of the structural model that are retrieved by simple estimations on families with children are sufficient to compute optimal subsidy rates on child-specific goods. In the less restrictive case where all types of goods are to be subsidized, the targeting effect of a subsidy - essentially the slopes of the Engel curves - must be recovered empirically. To achieve this, the easiest way consists in employing a Rothbarth-like method as described in Gronau (1991), which allows the econometrician to recover the share of income accruing to the child, provided that at least one good is not consumed by the child. This is the objective of on-going research (Bargain and Donni, 2009, and Dunbar et al., 2010). The identification of the targeting effect will allow extracting the set of (general) goods for which the subsidy will be most effective. 


\section{Appendix A: The Case of CARA Utility Functions}

To illustrate the properties of the sharing rule, let us consider the case where the utility functions are of the CARA form: $u^{g}=-\exp \left(-\alpha_{g}(\boldsymbol{p}) \cdot \phi_{g}\right)$, for $g=c, a$, where $\alpha_{g}(\boldsymbol{p})$ is an homogeneous function of order -1 in prices $\boldsymbol{p}$. First, the adult's and the child's Engel curves are easily computed using the Roy's identity:

$$
x_{k}^{a}=-\left(\frac{\partial \alpha_{a}(\boldsymbol{p}) / \partial p_{k}}{\alpha_{a}(\boldsymbol{p})}\right) \phi_{a}, \quad x_{k}^{c}=-\left(\frac{\partial \alpha_{c}(\boldsymbol{p}) / \partial p_{k}}{\alpha_{c}(\boldsymbol{p})}\right) \phi_{c}
$$

i.e., the impact of the income share is linear. Similarly, the child's share of income is linear and can be written as:

$$
\phi_{c}=\frac{\ln \alpha_{c}(\boldsymbol{p})-\ln \alpha_{a}(\boldsymbol{p})+\ln \rho}{\alpha_{a}(\boldsymbol{p})+\alpha_{c}(\boldsymbol{p})}+\frac{\alpha_{a}(\boldsymbol{p})}{\alpha_{a}(\boldsymbol{p})+\alpha_{c}(\boldsymbol{p})} \cdot Y ;
$$

thus adult's altruism influences the intercept of the sharing rule but not the slope. In the CARA specification, the individual measures of income fluctuation aversion are constant and correspond to $\alpha_{g}(\boldsymbol{p})$, so that the complementarity index $\theta$ is simply equal to $\alpha_{a}(\boldsymbol{p})+$ $\alpha_{c}(\boldsymbol{p})$. The value of the index is not invariant to changes in measurement units, hence its interpretation is complicated. Now let us write the individual demands as $x_{k}^{g}=a_{k}^{g} \phi_{g}$, where $a_{k}^{g}=-\left(\left(\partial \alpha_{g} / \partial p_{k}\right) / \alpha_{g}\right)$, and the sharing rule as $\phi=\eta_{1}+\eta_{2} Y$ so that $z_{c}=\eta_{1}+\eta_{2} Z_{c}$, where $\eta_{1}, \eta_{2}$ are the coefficients defined above. Let us suppose that the targeting effect is positive for good $k$, that is, $a_{k}^{c}>a_{k}^{a}$. In that case, the average demand for good $k$ over the $Z_{a}-$ population is simply equal to

$$
\begin{aligned}
E_{a}\left(x_{k}\right) & =\frac{1}{G} \times \int_{0}^{Z_{a}}\left[\left(a_{k}^{c}-a_{k}^{a}\right) \eta_{1}+\left(a_{k}^{a}\left(1-\eta_{2}\right)+a_{k}^{c} \eta_{2}\right) Y\right] f(Y) \cdot \mathrm{d} Y \\
& =A_{k}+B_{k} E_{a}(Y)
\end{aligned}
$$

where $A=\left(a_{k}^{c}-a_{k}^{a}\right) \eta_{1}>0$ and $B=\left(a_{k}^{a}\left(1-\eta_{2}\right)+a_{k}^{c} \eta_{2}\right)$ are the parameters of the household demand for good $k$. Using (32) and (33), we obtain the marginal impact of the subsidy at $s_{k}=0$ :

$$
\frac{\partial P}{\partial B}=-\frac{1}{z_{c}} \times \frac{H}{G} \times\left[\eta_{2}\left(A_{k}+B_{k} E_{c}(Y)\right)+\frac{a_{k}^{c}-a_{k}^{a}}{\theta}\right] \times\left[A_{k}+B_{k} E_{a}(Y)\right]^{-1},
$$

and the marginal impact of the transfer:

$$
\frac{\partial P}{\partial T}=-\frac{1}{z_{c}} \times \frac{H}{G} \times \eta_{2},
$$


Taking the difference between these two expressions and simplifying, we demonstrate that (from the no-subsidy situation) the subsidy is more efficient than the transfer if and only if the following condition is satisfied:

$$
\theta\left[E_{a}(Y)-E_{c}(Y)\right]<\frac{a_{k}^{c}-a_{k}^{a}}{\eta_{2} B_{k}}
$$

which simplifies to $\theta \eta_{2}^{2}\left[E_{a}(Y)-E_{c}(Y)\right]<1$ if $\operatorname{good} k$ is exclusively consumed by the child. In this case, the crucial parameters are the complementarity index $\theta$ and the propensity to spend total income for child's welfare $\eta_{2}$.

\section{Appendix B: Paternalism and (De)merit Goods}

To measure the impact of subsidies, we must compute the child's indirect utility function that takes into account the fact that the adult's decisions are not optimal from the planner's viewpoint. To do that, we define: $\bar{v}^{c}\left(\boldsymbol{p}, \phi_{c}\right)=\bar{u}^{c}\left(\boldsymbol{x}^{c}\left(\boldsymbol{p}, \phi_{c}\right)\right)$. This is not a traditional indirect utility function because the demands for goods are not optimal from the planner's perspective. In particular, the Roy's identity does not hold. Indeed, if we differentiate expression (26) with respect to $\phi_{c}$ and use the definition (27), we observe that

$$
\frac{\partial x_{i}^{c}\left(\boldsymbol{p}, \phi_{c}\right)}{\partial \phi_{c}}=\frac{\partial \bar{x}_{i}^{c}\left(\overline{\boldsymbol{p}}, \bar{\phi}_{c}\right)}{\partial \bar{\phi}_{c}}\left(\sum_{j=1}^{n} \bar{p}_{j} \frac{\partial x_{j}^{c}\left(\boldsymbol{p}, \phi_{c}\right)}{\partial \phi_{c}}\right) \text {. }
$$

Similarly, if we differentiate expression (26) with respect to $p_{j}$, we obtain:

$$
\frac{\partial x_{i}^{c}\left(\boldsymbol{p}, \phi_{c}\right)}{\partial p_{j}}=\frac{\partial \bar{x}_{i}^{c}\left(\overline{\boldsymbol{p}}, \bar{\phi}_{c}\right)}{\partial \bar{p}_{j}} \delta_{j}+\frac{\partial \bar{x}_{i}^{c}\left(\overline{\boldsymbol{p}}, \bar{\phi}_{c}\right)}{\partial \bar{\phi}_{c}}\left(\delta_{j} x_{j}^{c}+\sum_{k=1}^{n} \delta_{k} p_{k} \frac{\partial x_{k}^{c}\left(\boldsymbol{p}, \phi_{c}\right)}{\partial p_{j}}\right) .
$$

If we use the relation (35) and the Slutsky equation, with the following definitions:

$$
\sigma_{i j}=\frac{\partial x_{i}^{c}\left(\boldsymbol{p}, \phi_{c}\right)}{\partial p_{j}}+x_{j}^{c} \frac{\partial x_{i}^{c}\left(\boldsymbol{p}, \phi_{c}\right)}{\partial \phi_{c}}, \quad \bar{\sigma}_{i j}=\frac{\partial \bar{x}_{i}^{c}\left(\overline{\boldsymbol{p}}, \bar{\phi}_{c}\right)}{\partial \bar{p}_{j}}+x_{j}^{c} \frac{\partial \bar{x}_{i}^{c}\left(\overline{\boldsymbol{p}}, \bar{\phi}_{c}\right)}{\partial \phi_{c}},
$$

we can write expression (36) as:

$$
\sigma_{i j} \sum_{k=1}^{n} \bar{p}_{k} \frac{\partial x_{k}^{c}\left(\boldsymbol{p}, \phi_{c}\right)}{\partial \phi_{c}}=\delta_{j} \bar{\sigma}_{i j} \sum_{k=1}^{n} \bar{p}_{k} \frac{\partial x_{k}^{c}\left(\boldsymbol{p}, \phi_{c}\right)}{\partial \phi_{c}}+\frac{\partial x_{i}^{c}\left(\boldsymbol{p}, \phi_{c}\right)}{\partial \phi_{c}} \sum_{k=1}^{n} \bar{p}_{k} \sigma_{k j} .
$$

Multiplying both members by $p_{k}$, summing over each $k$ and using the Cournot and Engel aggregation conditions give:

$$
\sum_{k=1}^{n} \bar{p}_{k} \sigma_{k j}=\delta_{j}\left(\sum_{k=1}^{n} p_{k} \bar{\sigma}_{k j}\right)\left(\sum_{k=1}^{n} \bar{p}_{k} \frac{\partial x_{k}^{c}\left(\boldsymbol{p}, \phi_{c}\right)}{\partial \phi_{c}}\right)
$$


This relation establishes a link between the substitution effects associated to $\boldsymbol{x}^{c}\left(\boldsymbol{p}, \phi_{c}\right)$ and $\overline{\boldsymbol{x}}^{c}\left(\overline{\boldsymbol{p}}, \bar{\phi}_{c}\right)$ respectively. This expression as well as expression (35) above will be used to compute the Roy Identity for the paternalistic indirect utility function. First, the derivative of the indirect utility function with respect to $p_{k}$ is equal to:

$$
\frac{\partial \bar{v}^{c}}{\partial p_{j}}=\sum_{k=1}^{n} \frac{\partial \bar{u}^{c}}{\partial x_{k}^{c}} \frac{\partial x_{k}^{c}\left(\boldsymbol{p}, \phi_{c}\right)}{\partial p_{j}}=\lambda \sum_{k=1}^{n} \bar{p}_{k} \frac{\partial x_{k}^{c}\left(\boldsymbol{p}, \phi_{c}\right)}{\partial p_{j}}
$$

and, similarly, the derivative with respect to $\phi_{c}$ is equal to:

$$
\frac{\partial \bar{v}^{c}}{\partial \phi_{c}}=\sum_{k=1}^{n} \frac{\partial \bar{u}^{c}}{\partial x_{k}^{c}} \frac{\partial x_{k}^{c}\left(\boldsymbol{p}, \phi_{c}\right)}{\partial \phi_{c}}=\lambda \sum_{k=1}^{n} \bar{p}_{k} \frac{\partial x_{k}^{c}\left(\boldsymbol{p}, \phi_{c}\right)}{\partial \phi_{c}} .
$$

Thus, if we assume that $\partial \bar{v}^{c} / \partial \phi_{c} \neq 0$, we obtain:

$$
\frac{\partial \bar{v}^{c} / \partial p_{j}}{\partial \bar{v}^{c} / \partial \phi}=\frac{\sum_{k=1}^{n} \bar{p}_{k}\left(\partial x_{k}^{c}\left(\boldsymbol{p}, \phi_{c}\right) / \partial p_{j}\right)}{\sum_{k=1}^{n} \bar{p}_{k}\left(\partial x_{k}^{c}\left(\boldsymbol{p}, \phi_{c}\right) / \partial \phi_{c}\right)} .
$$

If we use the Slutsky equation and expressions (35) and (36) above, we obtain the following expression:

$$
\frac{\partial \bar{v}^{c} / \partial p_{k}}{\partial \bar{v}^{c} / \partial \phi_{c}}=-\left(x_{k}^{c}+\delta_{k} \sum_{j=1}^{N} p_{j} \bar{\sigma}_{j k}\right),
$$

where

$$
\bar{\sigma}_{j k}=\frac{\partial \bar{x}_{c}^{j}\left(\overline{\boldsymbol{p}}, \bar{\phi}_{c}\right)}{\partial \bar{p}_{k}}+x_{k}^{c} \frac{\partial \bar{x}_{c}^{j}\left(\overline{\boldsymbol{p}}, \bar{\phi}_{c}\right)}{\partial \bar{\phi}_{c}},
$$

is a substitution effect evaluated with the planner's preferences. To interpret this expression, let us note that $\delta_{k} \sum_{j=1}^{N} p_{j} \delta_{j} \bar{\sigma}_{j k}=0$ from the properties of compensated demands, so that expression (37) can be written as:

$$
\frac{\partial \bar{v}^{c} / \partial p_{k}}{\partial \bar{v}^{c} / \partial \phi}=-\left(x_{k}+\delta_{k} \sum_{j=1}^{N} p_{j}\left(1-\delta_{j}\right) \bar{\sigma}_{j k}\right) .
$$

Using these results and equation (18), the opposite of the Hicksian variation associated with the subsidy rise is equal to expression (28) in the main text.

\section{References}

[1] Allgood, S. and A. Snow (1998), "The marginal cost of raising tax revenue and redistributing income", Journal of Political Economy, 106, 1246-1273. 
[2] Bargain, O. and O. Donni (2009): "The Measurement of Child Costs: A RothbarthType Method Consistent with Scale Economies", IZA discussion paper.

[3] Becker, G.S. (1974), "A theory of social interactions", Journal of Political Economy, 82, 1063-1093

[4] Besley, T.J. (1988), "A Simple Model for Merit Good Arguments", Journal of Public Economics, 35, 371-383.

[5] Besley, T.J. (1990), "Means testing versus universal provision in poverty alleviation programmes", Economica, 57, 119-129.

[6] Besley, T.J. and R. Kanbur (1988), "Food subsidies and poverty alleviation", Economic Journal, 98, 701-719.

[7] Bhalotra, S. and C. Attfield (1998): "Intrahousehold Resource Allocation in Rural Pakistan: A Semiparametric Analysis", Journal of Applied Econometrics, 13, 463-480

[8] Blow, L., I. Walker and Y. Zhu (2010), "Who benefits from child benefits?", Economic Inquiry, forthcoming.

[9] Bourguignon, F. (1999), "The cost of children: May the collective approach to household behaviour help?", Journal of Population Economics, 12, 503-522.

[10] Browning M., and P.A. Chiappori (1998), "Efficient Intra-Household Allocations: A General Characterization and Empirical Tests," Econometrica, 66, 1241-1278.

[11] Browning, M., P.A. Chiappori and A. Lewbel (2006), "Estimating Consumption Economies of Scale, Adult Equivalence Scales, and Household Bargaining Power", Boston College Working Paper in Economics 588.

[12] Chiappori, P.-A. and O. Donni (2010), "Non-unitary Models of Household Behavior: A Survey". In: A. Molina (eds), Household Economic Behaviors, Berlin: Springer.

[13] Christiansen, V. (1983), "Some important properties of the social marginal utility of income", Scandinavian Journal of Economics, 85, 359-371.

[14] Cigno, A., A. Luporini and A. Pettini (2003), "Transfers to families with children as a principal-agent problem", Journal of Public Economics, 87, 1165-1177. 
[15] Cremer, H. and P. Pestieau (2001): "Non-linear taxation of bequests, equal sharing rules and the tradeoff between intra- and inter-family inequalities", Journal of Public Economics, 79, 35-53(19)

[16] Currie, J. and F. Gahvari (2008), "Transfers in cash and in-kind: theory meets the data", Journal of Economic Literature, 46, 333-383.

[17] Dauphin, A., A-R. El Lahga, B. Fortin and G. Lacroix (2011), "Are Children Decision-Makers Within the Household?", Economic Journal, forthcoming.

[18] Deaton, A. (1979), "Optimally Uniform Commodity Taxes", Economic Letters, 2, 357-361.

[19] Deaton, A. and J. Muellbauer (1980), Economics and Consumer Behavior. Cambridge: Cambridge University Press.

[20] Dickens, R. and D. T. Ellwood (2003), "Child poverty in Britain and the United States", Economic Journal, vol. 113, pp. F219-F239.

[21] Donni, O. (2009), "A simple approach to investigate intrahousehold allocation of private and public goods", Review of Economics and Statistics, 91, 617-28.

[22] Dunbar, G., A. Lewbel and K. Pendakur (2010), "Children's Resources in Collective Households: Identification, Estimation and an Application to Child Poverty in Malawi", Working Paper, Simon Fraser University \& Boston College.

[23] Edmonds, E. (2002), "Reconsidering the labeling effect for child benefits: evidence from a transition economy", Economics Letters, 76, 303-309.

[24] Gorman, W. M. (1953), "Community Preference Fields", Econometrica, 21, 63-80.

[25] Gornick, J.C. and M. Jäntti (2009): "Child povery in upper-income countries: lessons from the Luxembourg Income Study", in S.B. Kamerman, S. Phipps and A. BenArieh (eds), From child welfare to child wellbeing: an international perspective on knowledge in the service of making policy, New Yord: Springer.

[26] Gronau, R. (1988), "Consumption technology and the intrafamily distribution of resources - Adult equivalence scales reexamined". Journal of Political Economy, 96, 1183-1205. 
[27] Gronau, R. (1991), "The intrafamily allocation of goods - How to separate the adult from the child", Journal of Labor Economics, 9, 207-235.

[28] Haddad, L. and R. Kanbur (1992), "Intra-household Inequality and the theory of targeting". European Economic Review, 36, 373-378.

[29] Kanbur, R., and N. Stern (1987), "Transfers, targeting and poverty", Economic Policy, 5, 112-147.

[30] Kooreman, P. (2000), "The labeling effect of a child benefit system", American Economic Review, 90, 571-583.

[31] Lundberg S.J., R.A. Pollak and T.J. Wales (1997), “ Do Husbands and Wives Pool Their Resources? Evidence from the U.K. Child Benefit", Journal of Human Resources, $32,3,463-480$.

[32] Madden, D. (1999), "The kids are alright: who benefits from child benefits? An analysis using Irish data", UCD working paper.

[33] Manser M. and M. Brown, 1980, "Marriage and Household Decision-making: A Bargaining Analysis", International Economic Review, vol. 21, pp. 31-44.

[34] McElroy M.B. and M.J. Horney, 1981, "Nash-bargained Household Decisions: Toward a Generalization of the Theory of Demand", International Economic Review, vol. 22 , pp. 333-349.

[35] Musgrave, R. (1987), "Merit Goods", in: J. Eatwell, M. Milgate and P. Newman (eds.), The New Palgrave Dictionary of Economics, Palgrave Macmillan (Basingstoke and New York).

[36] Samuelson, P. (1956), "Social Indifference Curves". Quarterly Journal of Economics, $70,1-22$.

[37] Thaler, R. (1999), "Mental accounting matters", Journal of Behavioral Decision Making, 12, 183-206. 